\title{
Clinical and radiological outcomes in patients who underwent posterior lumbar interbody fusion: comparisons between unilateral and bilateral cage insertion
}

\author{
Jae Hwan Cho ${ }^{*}$, Chang Ju Hwang, Dong-Ho Lee and Choon Sung Lee
}

\begin{abstract}
Background: Although the original technique involves inserting two cages bilaterally, there could be situations that only allow for insertion of one cage unilaterally. However, only a few studies have compared the outcomes between unilateral and bilateral cage insertion. The purpose of this study was to compare the clinical and radiological outcomes in patients who underwent posterior lumbar interbody fusion (PLIF) between unilaterally and bilaterally inserted cages.

Methods: Among 206 eligible patients who underwent 1- or 2-level PLIF, 78 patients were 1:3 cohort-matched by age, sex, and operation level (group U, 19 patients with unilateral cages; and group B, 57 patients with bilateral cages). Fusion status was evaluated by computed tomography (CT) scans at postoperative 1 year. Clinical outcomes were measured by visual analog scale (VAS), Oswestry Disability Index (ODI), and EQ-5D. Radiological and clinical parameters were compared between the two groups. Risk factors for pseudarthrosis were also analyzed by multivariate analysis.
\end{abstract}

Results: The demographic data were not significantly different between the two groups. However, previous laminectomy, asymmetric disc collapse, and fusion at L5-S1 level were more frequently found in group $U(P=0.003, P=0.014$, and $P=0.014$, respectively). Furthermore, pseudarthrosis was more frequently observed in group $U(36.8 \%)$ than in group B (7.0\%) $(P=0.004)$. Back pain VAS was higher in group $U$ at postoperative 1 year $(P=0.033)$. Lower general activity function of EQ-5D was observed in group $U$ at postoperative 1 year $(P=0.035)$. Older age $(P=0.028)$, unilateral cage $(P=0.007)$, and higher bone mineral density $(P=0.033)$ were positively correlated with pseudarthrosis.

Conclusions: Unilaterally inserted cage might be a possible risk factor for pseudarthrosis when performing PLIF, which could be related with the difficult working conditions such as scars due to previous laminectomy or asymmetric disc collapse. Furthermore, suboptimal clinical outcomes are expected following PLIF with unilateral cage insertion at postoperative 1 year regardless of similar clinical outcomes at postoperative 2 year. Therefore, caution is advised when inserting cages unilaterally, especially under above-mentioned conditions in terms of its possible relationship with symptomatic pseudarthrosis.

*Correspondence: spinecjh@gmail.com

Department of Orthopedic Surgery, Asan Medical Center, University of Ulsan College of Medicine, 388-1, PungNap-2-dong, SongPa-gu, Seoul, South Korea permits use, sharing, adaptation, distribution and reproduction in any medium or format, as long as you give appropriate credit to the original author(s) and the source, provide a link to the Creative Commons licence, and indicate if changes were made. The images or other third party material in this article are included in the article's Creative Commons licence, unless indicated otherwise in a credit line to the material. If material is not included in the article's Creative Commons licence and your intended use is not permitted by statutory regulation or exceeds the permitted use, you will need to obtain permission directly from the copyright holder. To view a copy of this licence, visit http://creativecommons.org/licenses/by/4.0/. The Creative Commons Public Domain Dedication waiver (http://creativeco mmons.org/publicdomain/zero/1.0/) applies to the data made available in this article, unless otherwise stated in a credit line to the data. 
Keywords: Posterior lumbar interbody fusion, Cage, Outcomes, Cohort matching, Unilateral, Bilateral, Pseudarthrosis, Risk factor

\section{Background}

Posterior lumbar interbody fusion (PLIF) is a well-proven procedure to perform in patients who require stabilization following wide decompression for spinal stenosis or spondylolisthesis $[1,2]$. PLIF involves cage insertion through the disc space. Although two cages are inserted bilaterally in the original technique, situations can arise in which only one cage can be inserted unilaterally, such as in severe asymmetric disc space narrowing, severe adhesion due to previous laminectomy or discectomy, or anatomic root variation [3]. In the above cases, unilateral cage insertion, posterolateral fusion, or anterior lumbar interbody fusion could be considered as an alternative [4].

Several previous studies have compared the clinical and radiological outcomes of unilaterally and bilaterally inserted cages. A few studies have revealed the effectiveness of unilateral interbody cage insertion in terms of similar clinical and radiological outcomes compared to that of bilateral cage insertion if bilateral screw fixation was conducted [5, 6].

However, contrary to the previous belief, we experienced frequent pseudarthrosis when the cage was unilaterally inserted in the PLIF procedure. Thus, our basic hypothesis was that the postoperative fusion rate in cases with unilaterally inserted cages is inferior to those with bilateral cages. The main purpose of this study was to compare the clinical and radiological outcomes in patients who underwent PLIF between unilateral and bilateral cage groups.

\section{Methods}

\section{Patients and operative methods}

Among 206 consecutive, eligible patients who underwent 1- or 2-level PLIF for spinal stenosis or spondylolisthesis from March 2014 to January 2018 in our institution, a total of 78 patients were finally included in this study. Because of an unbalanced ratio between unilateral $(n=19)$ and bilateral $(n=187)$ cage insertion, 1:3 cohorts were matched by age, sex, and operation level (group U, 19 patients with unilateral cages; and group B, 57 patients with bilateral cages). The indication of PLIF was as follows: (1) spondylolisthesis, (2) symptomatic neural foraminal stenosis, (3) combined severe back pain because of severe facet degeneration.

All surgeries were performed by a single surgeon, and patients were followed up for more than 2 years. The operative procedure was conducted in a routine manner as follows: bilateral pedicle screw insertions, subtotal laminectomy, bilateral facetectomy, disc preparation, packing of local bone fragments in the anterior intervertebral space and PEEK (polyetheretherketone) cage insertion with bone graft material (local bone fragments with DBM or BMP-2). We did not experience the lack of bone graft even in revisional surgeries because we could get the morselized bone from additional laminectomy and medial total facetectomy. We usually tried to insert cages bilaterally, and we only inserted a cage unilaterally in specific conditions, such as in cases with a narrow working space or aberrant nerve root.

\section{Study variables}

Demographic data and operation-related data were obtained by electronic chart reviews. The visual analog scale (VAS), Oswestry Disability Index (ODI), and EuroQol 5-dimension questionnaire (EQ-5D) were used to evaluate clinical outcomes. The length of stay, operation time, estimated blood loss, bone graft material, and postoperative complications were also reviewed. Fusion status was evaluated by three-dimensional computed tomography (CT) scans at postoperative 1-year [7]. We defined bony fusion as existence of a bridging trabecular bone, mature bony trabeculae bridging the interbody space, or cortication at the peripheral edges of fusion masses between both endplates, and without cystic radiolucency in coronal and sagittal reconstructed images of thin-section CT scans [8]. If pseudarthrosis was found only one level in 2-level fusion cases, then this case was regarded as pseudarthrosis. If there was evidence of solid fusion for only one cage in bilaterally inserted cases, then this case was regarded as fusion. All patients were followed up at 1, 3, 6, and 12 months postoperatively, and yearly thereafter. This study was approved by our Institutional Review Board, which waived the requirement for informed consent given the retrospective nature of the analysis.

\section{Statistical analyses}

Demographic data, operation-related data, and clinical outcomes were compared between group $\mathrm{U}$ and group $\mathrm{B}$ by either the Student's t-test or chi-square test. Multivariate logistic regression analysis was performed to control for intervening factors. Further analysis in accordance with fusion status at 1-year postoperative was performed. Statistical analyses were performed using the Statistical Package for Social Sciences software, version 21.0 (SPSS, 
Chicago, IL), with $P$-values $<0.05$ considered to indicate statistical significance.

\section{Results}

The mean age of the participants was 65.4 years old, and the sex ratio was 10:9 (male:female). The ratio of operation levels was 9:10 ( 1 vs 2 level). There were no significant differences in demographic data between the two groups, with the exception of operation level (Table 1). We could insert cages bilaterally more easily at L4-5 level or above (77.2\% for group B and $42.1 \%$ for group U). However, 56.9\% (11/19) of group U included L5-S1 level.

The reasons for unilateral cage insertion were as follows: Eight asymmetric disc collapse, six severe adhesion, three suspicious nerve root variation, and two other reasons.

\section{Comparisons of clinical and radiological outcomes between group $\mathrm{U}$ and group $\mathrm{B}$}

There were no significant differences in hospital stay, operation time, and estimated blood loss between the two groups. However, a higher fusion rate was observed in group B (93.0\% in group B and $63.2 \%$ in group U), irrespective of the fact that similar bone graft material

Table 1 Demographic data of age, sex, operation level-matched cohort

\begin{tabular}{|c|c|c|c|c|}
\hline & Category & $\begin{array}{l}\text { Group } U \\
(N=19)\end{array}$ & $\begin{array}{l}\text { Group B } \\
(N=57)\end{array}$ & $P$ value \\
\hline Age (yr) & & $65.6 \pm 10.7$ & $65.3 \pm 9.0$ & 0.905 \\
\hline \multirow[t]{2}{*}{ Sex } & M & $10(52.6 \%)$ & $30(52.6 \%)$ & 1.000 \\
\hline & $\mathrm{F}$ & $9(47.4 \%)$ & $27(47.4 \%)$ & \\
\hline Height (cm) & & $160.0 \pm 8.7$ & $156.4 \pm 8.8$ & 0.125 \\
\hline Weight (kg) & & $66.4 \pm 9.9$ & $61.4 \pm 9.5$ & 0.053 \\
\hline $\mathrm{BMI}\left(\mathrm{kg} / \mathrm{m}^{2}\right)$ & & $25.9 \pm 2.4$ & $25.0 \pm 2.7$ & 0.229 \\
\hline BMD (T score) & & $-0.6 \pm 1.6$ & $-0.9 \pm 1.3$ & 0.515 \\
\hline \multirow[t]{2}{*}{ Smoking } & Y & $5(26.3 \%)$ & $6(10.5 \%)$ & 0.090 \\
\hline & N & $14(73.7 \%)$ & $51(89.5 \%)$ & \\
\hline \multirow[t]{2}{*}{ Number of Op. level } & 1 & $9(47.4 \%)$ & $27(47.4 \%)$ & 1.000 \\
\hline & 2 & $10(52.6 \%)$ & $30(52.6 \%)$ & \\
\hline \multirow[t]{5}{*}{ Op. level } & L3-4 & $1(5.3 \%)$ & $3(5.3 \%)$ & 0.014 \\
\hline & L3-4-5 & $5(26.3 \%)$ & $20(35.1 \%)$ & \\
\hline & $\llcorner 4-5$ & $2(10.5 \%)$ & $21(36.8 \%)$ & \\
\hline & L4-5-S1 & $5(26.3 \%)$ & $10(17.5 \%)$ & \\
\hline & L5-S1 & $6(31.6 \%)$ & $3(5.3 \%)$ & \\
\hline Previous laminectomy & Yes & $5(26.3 \%)$ & $1(1.8 \%)$ & 0.003 \\
\hline Asymmetric disc collapse $\mathrm{a}^{\mathrm{a}}$ & Yes & $6(31.5 \%)$ & $5(8.8 \%)$ & 0.014 \\
\hline
\end{tabular}

Mean and standard variation in continuous variables and number of cases in categorical variables

Group U: Unilateral cage insertion; Group B: Bilateral cage insertion

$M$ Male, F Female, $B M I$ Body mass index, BMD Bone mineral density

${ }^{a}$ Five or more degree of asymmetric disc wedging on the radiographs was used. In addition, more previous laminectomy at the same site and asymmetric disc wedging was found in group $\mathrm{U}(P=0.003$ and 0.014 , respectively). Although there were four cases of screw-related complications in group B, no postoperative neurologic compromise was found in either of the groups postoperatively. We did not experience revisional surgery during 2-year followup period. The overall operation-related data are summarized in Table 2.

The clinical and functional outcomes are described in Fig. 1 and Table 3. None of the preoperative variables showed significant differences between the two groups. The back pain VAS was significantly higher in group $\mathrm{U}$ than in group B at 1 year postoperative (4.2 vs 2.3 , $P=0.033)$; however, this difference disappeared at the 2 -year follow-up $(P=0.637)$. There were no significant differences in terms of leg pain VAS and ODI. There was a significant difference in EQ-5D (usual activities) at 1 year postoperative (2.5 in group $\mathrm{U}$ and 1.9 in group $\mathrm{B}, P=0.035)$, although this change disappeared at the 2-year follow-up $(P=0.230)$. The mobility ( 2.4 and 1.9 , $P=0.094)$ and self-care (2.0 vs $1.6, P=0.083)$ domain of EQ-5D showed better outcomes in group $B$ at 2 year postoperative, although this did not reach statistical significance. Representative cases are illustrated in Fig. 2 and Fig. 3.

Table 2 Comparisons of operation related data between 2 cohorts

\begin{tabular}{lllll}
\hline & Category & $\begin{array}{l}\text { Group U } \\
(\mathbf{N = 1 9 )}\end{array}$ & $\begin{array}{l}\text { Group B } \\
(\mathbf{N = 5 7 )}\end{array}$ & P-value \\
\hline $\begin{array}{llll}\text { Length of stay } \\
\text { Operation time }\end{array}$ & & $11.8 \pm 2.3$ & $12.0 \pm 3.2$ & 0.791 \\
$\begin{array}{l}\text { Estimated blood } \\
\text { loss }\end{array}$ & & $138.7 \pm 31.7$ & $151.1 \pm 36.9$ & 0.191 \\
$\begin{array}{l}\text { Bone graft } \\
\text { material }\end{array}$ & Local bone & $2(10.5 \%)$ & $8(14.0 \%)$ & 0.098 \\
& DBM & $3(15.8 \%)$ & $23(40.4 \%)$ & \\
Fusion state & BMP & $14(73.7 \%)$ & $26(45.6 \%)$ & \\
at 1Y & Yes & $12(63.2 \%)$ & $53(93.0 \%)$ & 0.004 \\
Complications & No & $7(36.8 \%)$ & $4(7.0 \%)$ & \\
& Screw related & $0(0.0 \%)$ & $4(7.0 \%)$ & 0.567 \\
& Dural tear & $2(10.5 \%)$ & $1(1.8 \%)$ & 0.152 \\
& Neurologic & $0(0.0 \%)$ & $0(0.0 \%)$ & NA \\
& FBSS & $1(5.3 \%)$ & $6(10.5 \%)$ & 0.672 \\
\hline
\end{tabular}

Mean and standard variation in continuous variables and number of cases in categorical variables

Group U: Unilateral cage insertion; Group B: Bilateral cage insertion

$D B M$ Demineralized bone matrix, BMP Bone morphogenetic protein, FBSS Failed back surgery syndrome 

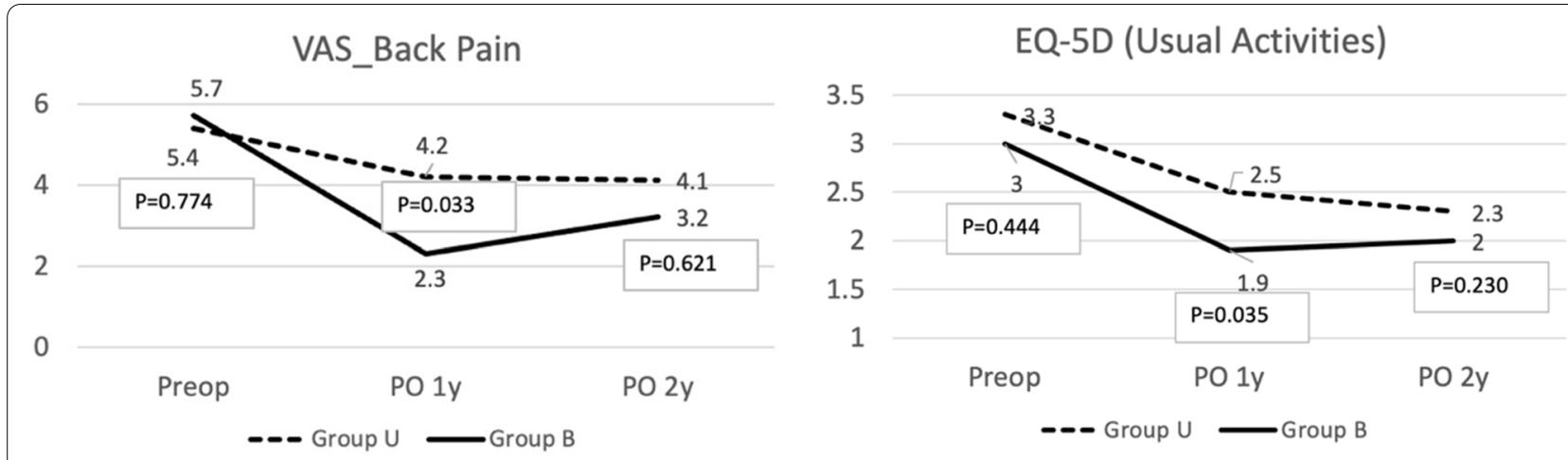

Fig. 1 Comparisons of clinical outcomes between group U (unilateral cage) and group B (bilateral cage). a Visual analog scale (VAS) of back pain, and $\mathbf{b}$ usual activities domain of EQ-5D

Table 3 Comparisons of clinical and functional outcomes between 2 groups

\begin{tabular}{lllll}
\hline & Periods & $\begin{array}{l}\text { Group U } \\
(\boldsymbol{N}=\mathbf{1 9})\end{array}$ & $\begin{array}{l}\text { Group B } \\
(\boldsymbol{N}=\mathbf{5 7})\end{array}$ & P value \\
\hline VAS_back & Preop & $5.4 \pm 2.4$ & $5.7 \pm 2.7$ & 0.774 \\
& PO 1y & $4.2 \pm 3.0$ & $2.3 \pm 2.7$ & 0.033 \\
& PO 2y & $4.1 \pm 2.8$ & $3.2 \pm 3.3$ & 0.621 \\
VAS_leg & Preop & $5.8 \pm 2.4$ & $5.9 \pm 2.8$ & 0.534 \\
& PO 1y & $2.0 \pm 2.9$ & $2.4 \pm 2.6$ & 0.637 \\
ODI & PO 2y & $3.3 \pm 3.1$ & $3.2 \pm 3.0$ & 0.878 \\
& Preop & $51.0 \pm 16.1$ & $53.0 \pm 18.1$ & 0.732 \\
EQ-5D (mobility) & PO 1y & $30.6 \pm 18.6$ & $24.0 \pm 15.3$ & 0.213 \\
& PO 2y & $35.0 \pm 18.0$ & $28.2 \pm 18.9$ & 0.192 \\
& Preop & $3.8 \pm 0.9$ & $3.4 \pm 0.9$ & 0.154 \\
EQ-5D (self-care) & PO 1y & $2.2 \pm 1.0$ & $2.0 \pm 0.9$ & 0.380 \\
& PO 2y & $2.4 \pm 1.0$ & $1.9 \pm 0.9$ & 0.094 \\
& Preop & $2.6 \pm 0.9$ & $2.6 \pm 1.0$ & 0.982 \\
& PO 1y & $2.0 \pm 1.0$ & $1.6 \pm 0.8$ & 0.135 \\
EQ-5D (usual activities) & PO 2y & $2.0 \pm 0.7$ & $1.6 \pm 0.8$ & 0.083 \\
& Preop & $3.3 \pm 1.1$ & $3.0 \pm 0.9$ & 0.444 \\
& PO 1y & $2.5 \pm 0.9$ & $1.9 \pm 0.9$ & 0.035 \\
& PO 2y & $2.3 \pm 1.0$ & $2.0 \pm 0.8$ & 0.230 \\
EQ-5D (anxiety/depres- & Preop & $2.4 \pm 1.0$ & $2.4 \pm 1.1$ & 0.996 \\
& PO 1y & $1.7 \pm 1.0$ & $1.6 \pm 0.8$ & 0.823 \\
& PO 2y & $1.8 \pm 0.9$ & $1.7 \pm 0.9$ & 0.663 \\
\hline EQ-5D (pain/discomfort) & Preop & $3.6 \pm 0.9$ & $3.5 \pm 1.0$ & 0.748 \\
& PO 1y & $2.8 \pm 1.0$ & $2.4 \pm 0.7$ & 0.126 \\
& PO 2y & $2.7 \pm 0.7$ & $2.4 \pm 0.9$ & 0.150 \\
& & & \\
& & &
\end{tabular}

VAS Visual analogue scale, ODI Oswestry disability index, EQ-5D EuroQol 5-dimension questionnaire

\section{Comparisons of various parameters in accordance with fusion status}

The fusion status at postoperative 1 year was associated with the number of cage insertions. The odds ratio for development of pseudarthrosis between group $U$ compared to group B was 7.73 (95\% confidence interval $[1.95,30.69])$. Only 1 pseudarthrosis case in 2-level PLIF cases showed partial union in one level (L5-S1) and pseudarthrosis in the other level (L4-5). We could not find any partial fusion case (solid fusion in one cage and pseudarthrosis in the other cage) in group B. In addition, younger age (63.8 vs 70.1 years, $P=0.028)$ and relatively lower bone mineral density (BMD) ( $-1.0 \mathrm{vs}$ $0.2, P=0.033$ ) were associated with postoperative bony fusion. However, sex, body mass index, bone graft material, previous laminectomy, radiological asymmetric disc wedging, operation level, and smoking were not associated with fusion (Table 4).

\section{Discussion}

The PLIF procedure is traditionally used to enhance intervertebral stability following decompression for spinal stenosis [9]. Initially, unicortical or bicortical bone grafts were inserted in both sides to enhance interbody fusion $[10,11]$. The use of cages was reported for the first time in 1993 [12], and cages have been used successfully since then $[13,14]$. Although cages were usually inserted bilaterally, the effectiveness of using unilateral cages has been also suggested, and comparable clinical outcomes and fusion rates have been observed in patients who underwent unilateral cage insertion.

We generally used bilateral cages in PLIF based on the belief that they have superior biomechanical stability, which could lead to better clinical and radiological outcomes. In one study, a higher immediate stability was proposed when PLIF was performed with bilateral cages compared to transforaminal lumbar interbody fusion (TLIF) [15]. Because the cage in TLIF has a wider surface than that in PLIF, the difference between unilateral and bilateral cages is probably greater in cases with PLIF. However, clinical studies have shown favorable results using single cages in an instrumented fusion. In one 


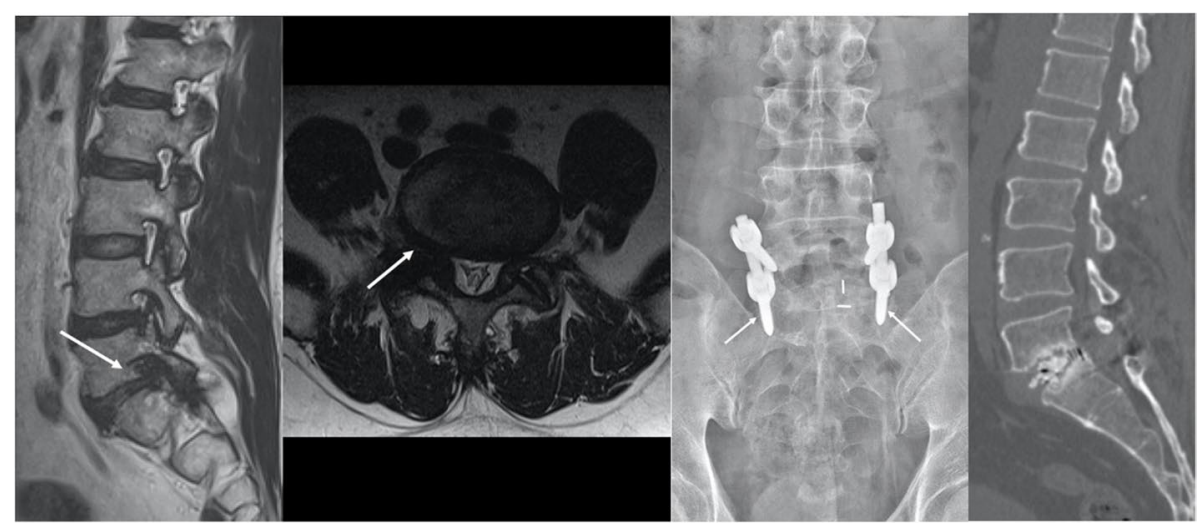

Fig. 2 Illustrative cases showing the pseudarthrosis following unilateral cage insertion. a A 56-year-old male patient with right buttock pain and leg weakness (BMD T-score, - 0.3). MRI (T2-weighted sagittal and axial) showed severe right foraminal stenosis (arrows). b A plain radiograph at postoperative 1 year showed radiolucency around S1 screws (arrows). c Definite pseudarthrosis was observed in the 1-year CT sagittal reconstruction image

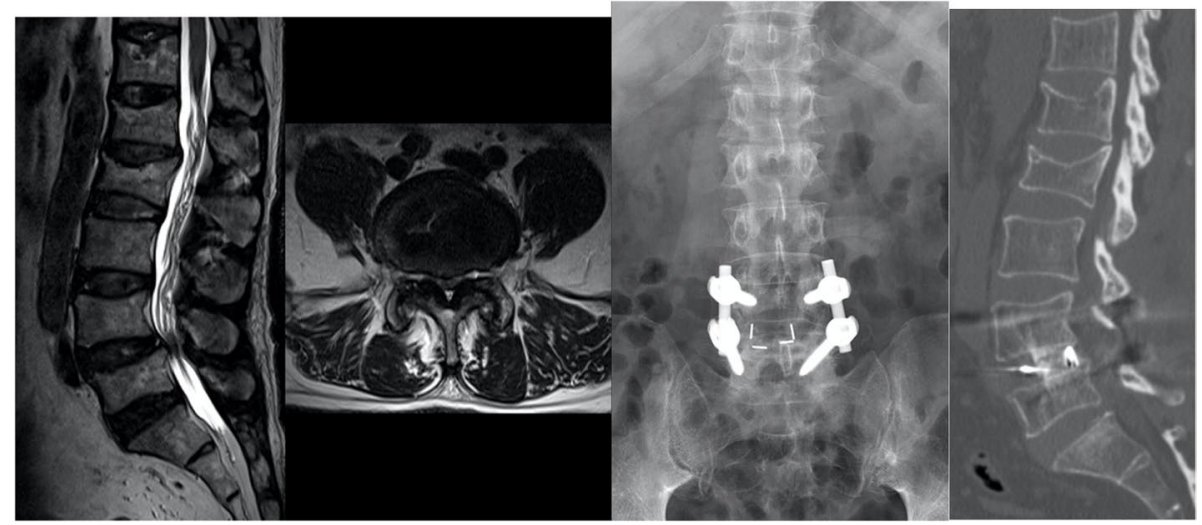

Fig. 3 Illustrative cases showing the solid fusion following bilateral cage insertion. a A 55-year-old male patient with low back pain with sciatica (BMDT-score - 1.6). MRI (T2-weighted sagittal and axial) showed severe central stenosis with degenerative spondylolisthesis. b No radiolucency was observed in the postoperative 1-year plain radiograph. c Solid fusion was observed in the 1-year CT sagittal reconstruction image

study, the rate of dural tear was higher in the bilateral cage group [16]. Shorter operative time and less blood loss in cases of two level fusion was also reported as an advantage of single cages [5]. However, few studies have revealed the superiority of clinical and radiological outcomes with single cage compared to with bilateral cages.

Recently, TLIF with a single cage is frequently considered because it has an advantage of less blood loss and shorter operative time. However, sometimes it is difficult to insert a cage with a larger surface area for TLIF in cases with a narrow disc space. In this case, it is easier to perform PLIF with smaller cages. However, there are certain conditions that prevent cage insertion. For example, root variation, such as dual root, severe fibrosis due to previous surgery, or failure to distraction of the narrow disc space because of severe disc degenerative changes are probable obstacles to prevent insertion of cages. In the above-mentioned situations, unilateral cage insertion was tried instead of posterolateral fusion (PLF) in this study due to the risk of sagittal malalignment.

Importantly, the union rate was inferior in unilateral cage group but not in the bilateral cage group (63.2\% vs $93.0 \%$ ) in the current study. The main reasons of this inferior fusion rate are thought to be (1) subsidence following over-distraction in cases with narrow disc spaces; (2) stress concentration on the cage as a result of asymmetric disc space on the coronal plane, such as degenerative scoliosis; and (3) a relatively small contacting area between endplates by the cage. More previous laminectomy, asymmetric disc wedging, and L5-S1 level were frequently found in group $\mathrm{U}$, the effect of those factors on pseudarthrosis were not revealed (Table 4). However, 
Table 4 Comparative analysis by the fused status at postoperative 1-year

\begin{tabular}{|c|c|c|c|c|c|c|c|}
\hline & Category & $\begin{array}{l}\text { Fusion } \\
(N=65)\end{array}$ & $\begin{array}{l}\text { Pseudarthrosis } \\
(N=11)\end{array}$ & $\begin{array}{l}P \text {-value } \\
\text { (Uni) }\end{array}$ & $\begin{array}{l}P \text {-value } \\
\text { (Multi) }\end{array}$ & Beta & SE \\
\hline Age & & $63.8 \pm 9.3$ & $70.1 \pm 9.7$ & 0.041 & 0.028 & 0.138 & 0.063 \\
\hline \multirow[t]{2}{*}{ Sex } & M & $24(36.9 \%)$ & $6(54.5 \%)$ & 0.269 & NA & NA & NA \\
\hline & $\mathrm{F}$ & $41(63.1 \%)$ & $5(45.5 \%)$ & & & & \\
\hline \multirow[t]{2}{*}{ Cages } & Unilateral & $12(18.5 \%)$ & $7(63.6 \%)$ & 0.004 & 0.007 & 2.429 & 0.901 \\
\hline & Bilateral & $53(81.5 \%)$ & $4(36.4 \%)$ & & & & \\
\hline $\mathrm{BMI}$ & & $25.0 \pm 2.4$ & $27.0 \pm 3.2$ & 0.019 & 0.069 & 0.333 & 0.183 \\
\hline $\mathrm{BMD}$ & & $-1.0 \pm 1.2$ & $0.2 \pm 1.7$ & 0.006 & 0.033 & 0.708 & 0.332 \\
\hline \multirow[t]{3}{*}{ Bone graft material } & Local bone & $8(12.3 \%)$ & $1(9.1 \%)$ & 0.759 & NA & NA & NA \\
\hline & DBM & $23(35.4 \%)$ & $3(27.3 \%)$ & & & & \\
\hline & BMP & $33(50.8 \%)$ & $7(63.6 \%)$ & & & & \\
\hline Previous laminectomy & $\begin{array}{l}Y \\
N\end{array}$ & $\begin{array}{l}4(7.4 \%) \\
61(92.6 \%)\end{array}$ & $\begin{array}{l}2(18.2 \%) \\
9(91.8 \%)\end{array}$ & 0.207 & NA & NA & NA \\
\hline Asymmetric disc wedging ${ }^{a}$ & $\begin{array}{l}Y \\
N\end{array}$ & $\begin{array}{l}9(13.8 \%) \\
56(86.2 \%)\end{array}$ & $\begin{array}{l}2(18.2 \%) \\
9(91.8 \%)\end{array}$ & 0.656 & NA & NA & NA \\
\hline Number of Op. level & & $1.58 \pm 0.50$ & $1.55 \pm 0.52$ & 0.811 & NA & NA & NA \\
\hline \multirow[t]{5}{*}{ Level } & L3-4 & $2(3.1 \%)$ & $1(9.1 \%)$ & 0.890 & NA & NA & NA \\
\hline & L3-4-5 & 23 (35.4\%) & $3(27.3 \%)$ & & & & \\
\hline & $\llcorner 4-5$ & $12(18.5 \%)$ & $2(18.2 \%)$ & & & & \\
\hline & L4-5-S1 & 15 (23.1\%) & $3(27.3 \%)$ & & & & \\
\hline & L5-S1 & 13 (20.0\%) & $2(18.2 \%)$ & & & & \\
\hline \multirow[t]{2}{*}{ Smoking } & Y & 9 (13.8\%) & $2(18.2 \%)$ & 0.656 & NA & NA & NA \\
\hline & $\mathrm{N}$ & 56 (86.2\%) & 9 (81.8\%) & & & & \\
\hline
\end{tabular}

Mean and standard variation in continuous variables and number of cases in categorical variables

$M$ Male, $F$ Female, BMI Body mass index, BMD Bone mineral density, DBM Demineralized bone matrix, BMP Bone morphogenetic protein

a Five or more degree of asymmetric disc wedging on the radiographs

above-mentioned conditions could be risk factors of nonunion $[17,18]$, although the risk factors of nonunion have not been clearly defined until now. In general, those factors are regarded as difficult conditions for performing spinal surgery. The reason of higher proportion of L5-S1 in group $U$ is not clear. However, frequently found unilateral disc collapse at L5-S1 might be one of the reasons, which could make it hard to insert a cage in severely collapsed side. Failure to reveal the effect of high proportion of L5-S1 in group U on pseudarthrosis is thought to be small sample size, which could be actual reason of inferior outcomes at postoperative 1-year. In this regard, difficult conditions to performing cage insertion such as limited bone stock due to previous laminectomy and disc space collapse at L5-S1 level could be more important factors. However, this could not be revealed by our study due to small sample size in group $U$.

The effect of nonunion on the postoperative symptoms also has been very controversial. Although back pain VAS and usual activity domain of EQ-5D showed inferior outcomes in postoperative $1 \mathrm{yr}$ in group $\mathrm{U}$, this difference disappeared in 2-yr follow-up. Many confounding factors could involve in this result, which made it difficult to interpret the result. In the past, many studies proposed no differences of clinical outcomes regardless of fusion status postoperatively $[19,20]$. However, a recent metaanalysis showed a superior result of the fused group in both clinical and functional outcomes [21]. This finding explains the increased back pain and lower functional scores in patients who underwent PLIF with unilateral cages, as well as the higher pseudarthrosis rate. However, many studies comparing TLIF with PLIF showed no differences in clinical and radiological outcomes, although fewer complication rates were noted in patients with TLIF [22, 23]. The comparable fusion rate with TLIF could be explained by the wider contact area of the cage used in TLIF.

Interestingly, we found two additional independent risk factors for pseudarthrosis: older age and higher BMD. The relationship between age and nonunion was also supported by one previous study, although many studies found no relationship between age and fusion rate [24, 25]. However, a few previous studies suggested that osteoporosis is related to a higher rate of nonunion, which disputed our results, although many other studies also denied the relationship between BMD and nonunion [18, 
26]. However, we think the more degenerative process such as sclerotic change could be related with the disc degeneration and collapse, which means the difficulty of cage insertion. Sometimes, bone density was checked to be higher due to the severe degeneration [27]. So, we did not think higher BMD itself is not the real cause of pseudarthrosis. In this regard, thorough investigation with a larger sample size might reveal the effect of demographic variables, such as age and BMD on the radiological outcome.

There are a few limitations to this retrospective study. First, the number of patients in each group was unbalanced, because we always tried to insert cages bilaterally, except in specific conditions. As a result, we performed 1:3 cohort matching to minimize the selection bias. Second, defining fusion status by CT is controversial; although many studies use CT to check the fusion status postoperatively, this method also has type I and type II errors, and is subjective. However, the diagnostic accuracy of $\mathrm{CT}$ to check pseudarthrosis is reported to be superior to that of lumbar radiographs [28]. Third, we could not reveal the previously known risk factors for nonunion, such as smoking, because of the relatively small sample size. Fourth, we did not check routine 2-year CT to analyzed fusion status, which made it impossible to analyze the effect of fusion rate on clinical outcomes in postoperative 2-year. However, we believed this study reflected the real clinical setting such as unavoidable unilateral cage insertion by various conditions.

\section{Conclusions}

In conclusion, unilaterally inserted cage might be a possible risk factor for pseudarthrosis when performing PLIF, which could be related with the difficult working conditions such as scars due to previous laminectomy or asymmetric disc collapse. Furthermore, suboptimal clinical outcomes are expected following PLIF with unilateral cage insertion at postoperative 1 year regardless of similar clinical outcomes at postoperative 2 year. Therefore, caution is advised when inserting cages unilaterally, especially under above-mentioned conditions in terms of its possible relationship with symptomatic pseudarthrosis.

\section{Abbreviations}

PLIF: Posterior lumbar interbody fusion; VAS: Visual analog scale; ODI: Oswestry Disability Index; EQ-5D: EuroQol 5-dimension questionnaire; CT: Computed tomography; BMD: Bone mineral density; TLIF: Transforaminal lumbar interbody fusion.

\section{Acknowledgements}

Not applicable.

\section{Authors' contributions}

$\mathrm{JHC}$; conception and design, analysis and interpretation of data, statistical analysis, drafting the manuscript. $\mathrm{CJH}$; acquisition of data, critical revision of manuscript. DHL; acquisition of data, critical revision of manuscript. CSL; critical revision of manuscript, administrative support. The author(s) read and approved the final manuscript.

Funding

This study was not supported by external funding.

\section{Availability of data and materials}

The datasets used and/or analysed during the current study are not publicly available due to limitations of ethical approval involving the patient data and anonymity but are available from the corresponding author on reasonable request.

\section{Declarations}

\section{Ethics approval and consent to participate}

All methods in this study were carried out in accordance with relevant guidelines and regulations.

This study was approved by the Institutional Review Board of Asan Medical Center. The need for written informed consent was waived by the Institutional Review Board ethics committee of Asan Medical Center due to retrospective nature of the study.

\section{Consent for publication}

Not applicable.

\section{Competing interests}

The authors declare that they have no competing interests.

Received: 23 March 2021 Accepted: 27 October 2021

Published online: 17 November 2021

\section{References}

1. Elfiky TA, Patil ND, Allam Y, Ragab R. Endplate changes with Polyetheretherketone cages in posterior lumbar Interbody fusion. Asian Spine J. 2020;14:229-37.

2. Kim YH, Ha KY, Rhyu KW, Park HY, Cho CH, Kim HC, et al. Lumbar Interbody fusion: techniques, Pearls and Pitfalls. Asian Spine J. 2020;14:730-41.

3. Schmidt CK, Rustagi T, Alonso F, Loukas M, Chapman JR, Oskouian RJ, et al. Nerve root anomalies: making sense of a complicated literature. Childs Nerv Syst. 2017;33:1261-73.

4. König MA, Ebrahimi FV, Nitulescu A, Behrbalk E, Boszczyk BM. Early results of stand-alone anterior lumbar interbody fusion in iatrogenic spondylolisthesis patients. Eur Spine J. 2013;22:2876-83.

5. Lee $\mathrm{JH}$, Lee $\mathrm{JH}$, Yoon KS, Kang SB, Jo CH. Comparative study of unilateral and bilateral cages with respect to clinical outcomes and stability in instrumented posterior lumbar interbody fusion. Neurosurgery. 2008;63:109-13.

6. Fogel GR, Toohey JS, Neidre A, Brantigan JW. Is one cage enough in posterior lumbar interbody fusion: a comparison of unilateral single cage interbody fusion to bilateral cages. J Spinal Disord Tech. 2007;20:60-5.

7. Kim GU, Chang MC, Kim TU, Lee GW. Diagnostic modality in spine disease: a review. Asian Spine J. 2020;14:910-20.

8. Brantigan JW, Steffee AD. A carbon fiber implant to aid interbody lumbar fusion. Two-year clinical results in the first 26 patients. Spine. 1993;18:2106-7.

9. Lee BH, Moon SH, Suk KS, Kim HS, Yang JH, Lee HM. Lumbar spinal stenosis: pathophysiology and treatment principle: a narrative review. Asian Spine J. 2020;14:682-93.

10. Lin PM, Cautilli RA, Joyce MF. Posterior lumbar interbody fusion. Clin Orthop Relat Res. 1983;180:154-68.

11. Takeda M. Experience in posterior lumbar interbody fusion: unicortical versus bicortical autologous grafts. Clin Orthop Relat Res. 1985;193:120-6.

12. Brantigan JW, Steffee AD. A carbon fiber implant to aid interbody lumbar fusion. Two-year clinical results in the first 26 patients. Spine (Phila Pa). 1976;1993(18):2106-7. 
13. Agazzi S, Reverdin A, May D. Posterior lumbar interbody fusion with cages: an independent review of 71 cases. J Neurosurg. 1999;91(2 Suppl):186-92.

14. Trouillier H, Birkenmaier C, Rauch A, Weiler C, Kauschke T, Refior HJ. Posterior lumbar interbody fusion (PLIF) with cages and local bone graft in the treatment of spinal stenosis. Acta Orthop Belg. 2006;72:460-6.

15. Sim HB, Murovic JA, Cho BY, Lim TJ, Park J. Biomechanical comparison of single-level posterior versus transforaminal lumbar interbody fusions with bilateral pedicle screw fixation: segmental stability and the effects on adjacent motion segments. J Neurosurg Spine. 2010;12:700-8.

16. Molinari RW, Sloboda J, Johnstone FL. Are 2 cages needed with instrumented PLIF? A comparison of 1 versus 2 interbody cages in a military population. Am J Orthop (Belle Mead NJ). 2003:32:337-43 discussion 343.

17. Han SH, Hyun SJ, Jahng TA, Kim KJ. A comparative radiographic analysis of fusion rate between $\mathrm{L} 4-5$ and $\mathrm{L} 5-\mathrm{S} 1$ in a single level posterior lumbar Interbody fusion. Korean J Spine. 2015;12:60-7.

18. Formica M, Vallerga D, Zanirato A, Cavagnaro L, Basso M, Divano S, et al. Fusion rate and influence of surgery-related factors in lumbar interbody arthrodesis for degenerative spine diseases: a meta-analysis and systematic review. Musculoskelet Surg. 2020;104:1-15.

19. DePalma AF, Rothman RH. The nature of pseudarthrosis. Clin Orthop Relat Res. 1968:59:113-8.

20. Burkus JK, Gornet MF, Dickman CA, ZdeblickTA. Anterior lumbar interbody fusion using rhBMP-2 with tapered interbody cages. J Spinal Disord Tech. 2002;15:337-49.

21. Noshchenko A, Lindley EM, Burger EL, Cain CM, Patel W. What is the clinical relevance of radiographic nonunion after single-level lumbar Interbody arthrodesis in degenerative disc disease?: a Meta-analysis of the YODA project database. Spine (Phila Pa). 1976;2016(41):9-17.
22. Zhang Q, Yuan Z, Zhou M, Liu H, Xu Y, Ren Y. A comparison of posterior lumbar interbody fusion and transforaminal lumbar interbody fusion: a literature review and meta-analysis. BMC Musculoskelet Disord. 2014;15:367.

23. de Kunder SL, van Kuijk SMJ, Rijkers K, Caelers I, van Hemert WLW, de Bie RA, et al. Transforaminal lumbar interbody fusion (TLIF) versus posterior lumbar interbody fusion (PLIF) in lumbar spondylolisthesis: a systematic review and meta-analysis. Spine J. 2017;17:1712-21.

24. Kim DH, Lee N, Shin DA, Yi S, Kim KN, Ha Y. Matched comparison of fusion rates between hydroxyapatite demineralized bone matrix and autograft in lumbar Interbody fusion. J Korean Neurosurg Soc. 2016;59:363-7.

25. Konomi T, Yasuda A, Fujiyoshi K, Yato Y, Asazuma T. Incidences and risk factors for postoperative non-union after posterior lumbar Interbody fusion with closed-box titanium spacers. Asian Spine J. 2020;14:106-12.

26. Okuyama K, Abe E, Suzuki T, Tamura Y, Chiba M, Sato K. Influence of bone mineral density on pedicle screw fixation: a study of pedicle screw fixation augmenting posterior lumbar interbody fusion in elderly patients. Spine J. 2001;1:402-7.

27. Zou D, Li W, Deng C, Du G, Xu N. The use of CT Hounsfield unit values to identify the undiagnosed spinal osteoporosis in patients with lumbar degenerative diseases. Eur Spine J. 2019;28:1758-66.

28. Gruskay JA, Webb ML, Grauer JN. Methods of evaluating lumbar and cervical fusion. Spine J. 2014;14:531-9.

\section{Publisher's Note}

Springer Nature remains neutral with regard to jurisdictional claims in published maps and institutional affiliations.
Ready to submit your research? Choose BMC and benefit from:

- fast, convenient online submission

- thorough peer review by experienced researchers in your field

- rapid publication on acceptance

- support for research data, including large and complex data types

- gold Open Access which fosters wider collaboration and increased citations

- maximum visibility for your research: over $100 \mathrm{M}$ website views per year

At BMC, research is always in progress.

Learn more biomedcentral.com/submissions 